\title{
Two new species of Phalangopsis Serville, 1831 (Orthoptera: Grylloidea: Phalangopsidae) from Brazilian Amazon Forest
}

\author{
CARINA M. MEWS ${ }^{1,2}$ and CARLOS F. SPERBER ${ }^{2}$ \\ ${ }^{1}$ Programa de Pós-Graduação em Entomologia, Departamento de Biologia Animal, Universidade Federal de Viçosa, \\ Av. P.H. Rolfs s/n, 36570-000 Viçosa, MG, Brasil \\ ${ }^{2}$ Laboratório de Orthopterologia, Departamento de Biologia Geral, Universidade Federal de Viçosa, \\ Av. P.H. Rolfs s/n, 36570-000 Viçosa, MG, Brasil \\ Manuscript received on June 29, 2007; accepted for publication on April 10, 2008; \\ presented by ALEXANDER W.A. KELLNER
}

\begin{abstract}
We describe here two new species of the genus Phalangopsis Serville, 1831 from the Brazilian Amazon Forest. The male genitalia and the female copulatory papilla were described, and a combination of diagnostic characteristics was given to separate both new species from the other described species. The principal morphological characteristics of this genus were discussed.
\end{abstract}

Key words: neotropical region, Brazil, crickets, Phalangopsini.

\section{INTRODUCTION}

The Phalangopsinae is represented in Brazil by six tribes and 11 genera (Eades et al. 2007). The genus Phalangopsis Serville 1831 (Grylloidea, Phalangopsidae, Phalangopsini) has six described species (Eades et al. 2007): P. longipes Serville 1831, P. gaudichaudi Saussure 1874, P. speluncae (Melo-Leitão 1937), P. carvalhoi CostaLima and Costa Leite 1953, P. aureopubescens (Wiendl 1970) and P. flavilongipes Desutter-Grandcolas 1992.

The genus is characterized by large individuals with a spider-like form, with very long palpi, tarsomeres and legs. The phallic complex has developed median lobes, dorsally elevated, hook-shaped lateral lobes, long endophallic sclerite and reduced endophallic apodeme and rami (Desutter 1990, Desutter-Grandcolas 1992).

These crickets live in the forest litter and are active at night, hiding during the day in caves or other natural cavities (Desutter 1990, Desutter-Grandcolas 1992).

The genus Phalangopsis was considered close to Aclodae group (Desutter 1990), however after the de-

Correspondence to: Carlos Frankl Sperber

E-mail: sperber@ufv.br scription of Philippopsis Desutter-Grandcolas 1992, the group classification and phylogenetic relationships became questionable and still need to be re-established. The state of knowledge of this group is still incipient and the lack of information on Phalangopsini hinders a new analysis.

In the present work we describe two new species of Phalangopsis from the Brazilian Amazon Forest, providing information on male and female genitalia.

\section{MATERIALS AND METHODS}

Six specimens of $P$. arenita sp. nov., and three specimens of P. bauxitica sp. nov. conserved in $70 \%$ ethanol solution were lent to the Orthopterology laboratory (Federal University of Viçosa) by the Entomological Collection of INPA (National Institute of Amazonian Research).

Analyses, comparisons and descriptions of general external morphology were made under a Leica MZ16. Measurements were taken under an MBS-9 stereomicroscope with a special scale ocular lens. Images were arranged and standardized using image editing software.

To characterize male fore wing the nomenclature 
proposed by Otte (1992) was used. For the male genitalia and the female copulatory papilla of Phalangopsis species, the nomenclature proposed by Desutter (1987, 1988) was used, with the modifications by DesutterGrandcolas (2003). P. arenita sp. nov. and P. bauxitica sp. nov. specimens were compared with published descriptions (Serville 1931, Saussure 1874, Melo-Leitão 1937, Costa-Lima and Costa-Leite 1953, Wiendl 1970, Desutter-Grandcolas 1992) and drawings of the Phalangopsis species (Desutter-Grandcolas 1992).

\section{Phalangopsis arenita Mews and Sperber sp. nov.} (Figs. 1-3)

Holotype. 1 male: vi. 1987, Gruta do Maroaga, Estrada de Balbina, Presidente Figueiredo, AM, Brasil (A.L. Henriques leg), INPA.

Etymology. The specific epithet is derived from the Latin word "arena"; which means arenite, the typical geological formation of the Maroaga cave.

Diagnosis. This species can be distinguished from the other Phalangopsis through the following combination of characteristics: (i) ocelli present, forming an equilateral triangle; (ii) a rounded fore wing covering the first abdominal tergite (Fig. 1C); (iii) stridulatory vein and pars stridens (24 teeth) present; (iv) tympanum present on the outer face of the fore tibia. Male genitalia: (v) pseudepiphallic lateral lobes bent to the frontal face, hook-shaped, with small hairs at the base of the pseudepiphallic lateral lobes (Fig. 2C); (vi) pseudepiphallic parameres wide, reaching the apex of the lateral lobes (Fig. 2B); (vii) pseudepiphallic median lobes forming a $30^{\circ}$ angle with the lateral lobe (Fig. 2C); (viii) ectophallic fold internal to the medium lobe, narrow and straight. Female genitalia: (ix) copulatory papilla elongated and sub-angular (Fig. 3A-C).

Male. Measurements $(\mathrm{mm})(\mathrm{n}=4)$ : body length 15.40 16.90; maximum eye width $3.40-3.60$; pronotal length 2.70-2.80; pronotal width 4.50-4.60; hind femur length 17.50-19.40; hind tibia length 22.60-23.00; wing width 3.20-3.50; wing length 2.50-2.80. Head light brown coloring. The top of the head dark brown, vertex light brown, and light brown, not prominent, fastigium. Gena with medium brown strip below the compound eye (Fig. 1A). Maxillary palpi truncate on the apex, with a whitish light yellow color. Elongated face in frontal view (Fig. 1B). Three reduced ocelli present, forming an equilateral triangle. Light brown scape. Antennae uniformly yellowish light brown. Body yellowish light brown. Pronotum dark brown with a lighter colored median depression; pronotum narrow with prominent lateral lobes. Fore wing covering the first abdominal tergite (Fig. 1A), brown coloring except for the border, which is white; round-shaped (Fig. 1C). $\mathrm{Sc}, \mathrm{Cu}_{1}$ and $\mathrm{Cu}_{2}$ (stridulatory vein) of fore wing present, pars stridens with 24 teeth, a Sc vein separates the dorsal champ from the lateral field, and $\mathrm{Cu}_{1}$ outlines the wing (Fig. 1C). Posterior border of the wing is intumesced, glandular and pubescent (Fig. 1A - stippled area). Tympanum reduced on the outer face of the anterior tibia, dropshaped. Fore and median femur yellowish light brown; fore and median tibiae yellowish light brown; fore and median tarsomeres yellowish light brown. Hind femur light brown, with a lighter colored strip in the middle, observed from an external lateral view, and darker transversal stripes on the superior dorsum. Hind tibia with four pairs of sub-apical spurs, the external always larger than the internal, 23 spines on the inner margin between the sub-apical spurs and 34 on the outer margin. Apical spurs: external smaller than internal. Supra-anal plate rounded at the apex (Fig. 1D). Subgenital plate wider than long (Fig. 1E). Male genitalia: pseudepiphallic lateral lobes with the same diameter along all extension, bent at the apex, forming a hook (Fig. 2A), with small hairs at the base of the pseudepiphallic lateral lobes (Fig. 2C); pseudepiphallic parameres wide, reaching the apex of the pseudepiphallic median lobe (Fig. 2B); pseudepiphallic median lobes forming a $30^{\circ}$ angle with the lateral lobe (Fig. 2C); base of the pseudepiphallus laterally narrow; ectophallic arc in anterior position (Fig. 2A-C); ectophallic fold internal to the medium lobe, narrow and straight (Fig. 2A). Ectophallic apodeme basal, short and wide. Endophallic sclerite small, as a simple "guiding rod" (Fig. 2A-C).

Female. Measurements $(\mathrm{mm})(\mathrm{n}=2)$ : body length 17.00-17.10; maximum eye width 2.90-3.00; pronotal length $2.85-2.90$; pronotal width $4.40-4.80$; hind femur length 18.10-19.50; hind tibia length 21.50-22.60; ovipositor length 14.50-15.50. General color pattern similar to the male. Brown ovipositor. Sub-apical spurs 

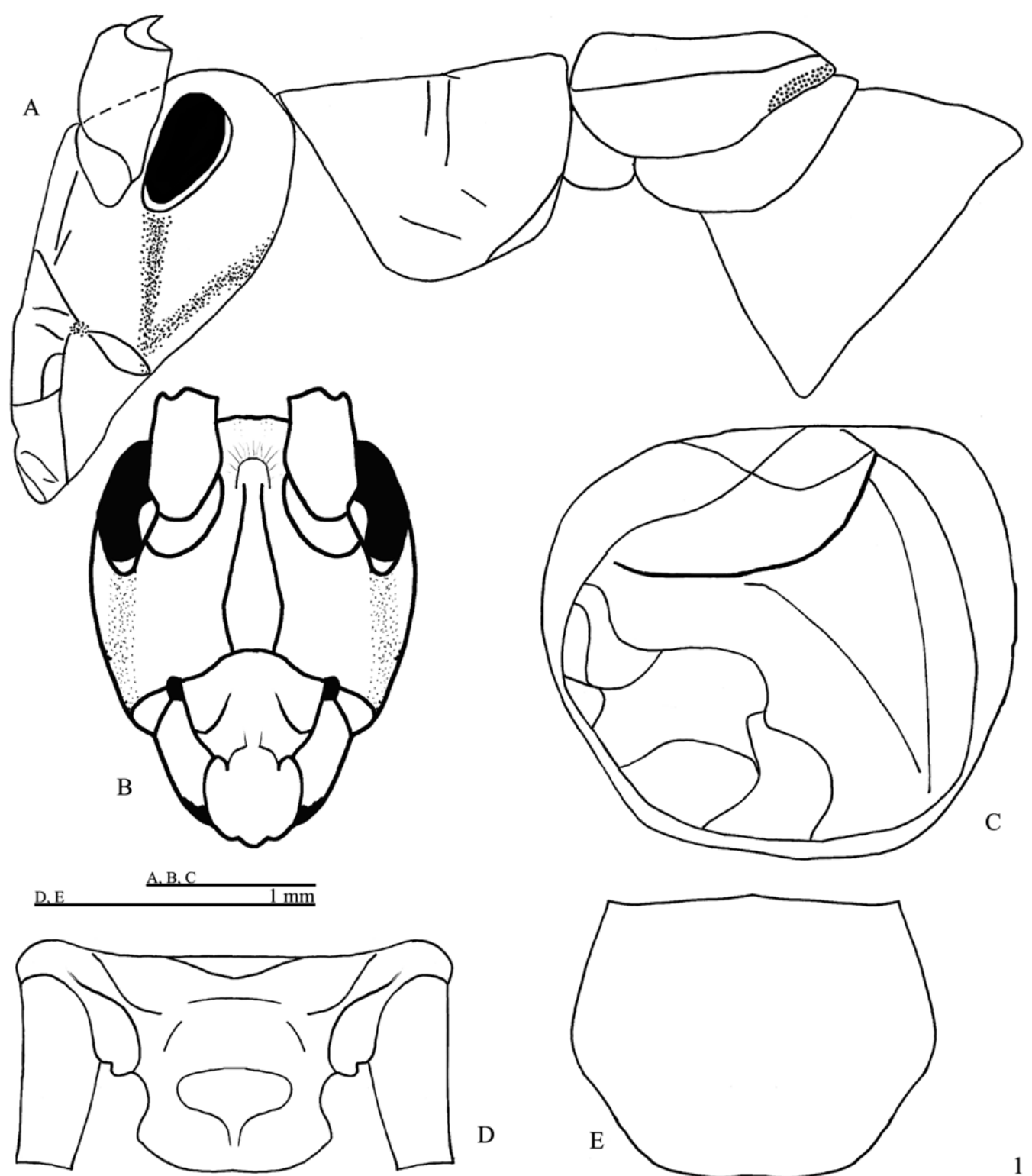

D

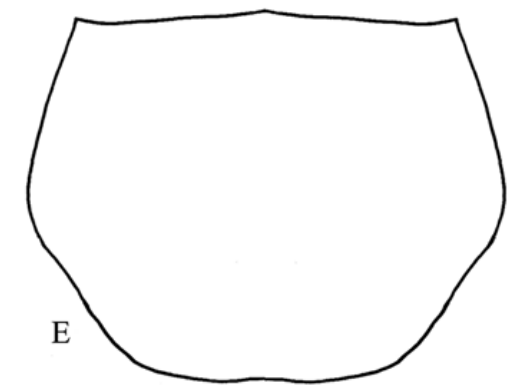

Fig. 1 - Male of Phalangopsis arenita sp. nov. A. Lateral view of the head and pronotum. B. Frontal view of the head. C. Dorsal view of the forewing. D. Supra-anal plate. E. Subgenital plate.

on the hind tibia displayed as follows: three on the inner margin and four on the outer margin (3 pairs + one subapical spur), the external always larger than the internal, 23 spines on the inner margin between the sub-apical spurs, and 31 on the outer margin. Seven apical spurs, being the external smaller than the internal. Copulatory papilla elongate, sub-angular, with membranous tip curved dorsally (Fig. 3A-C). Supra-anal plate as in Figure $3 \mathrm{D}$ and subgenital plate wider than long (Fig. 3E).
Remarks. Some specimens are darker than the holotype. On tibia III of one male paratype, the sub-apical spurs are displayed as follows: three on the inner margin and five on the outer margin.

Material examined. Holotype, allotype, four paratypes: three males and one female: vi. 1987, Gruta do Maroaga, Estrada de Balbina, Presidente Figueiredo, AM, Brasil, (A. L. Henriques leg), INPA. 


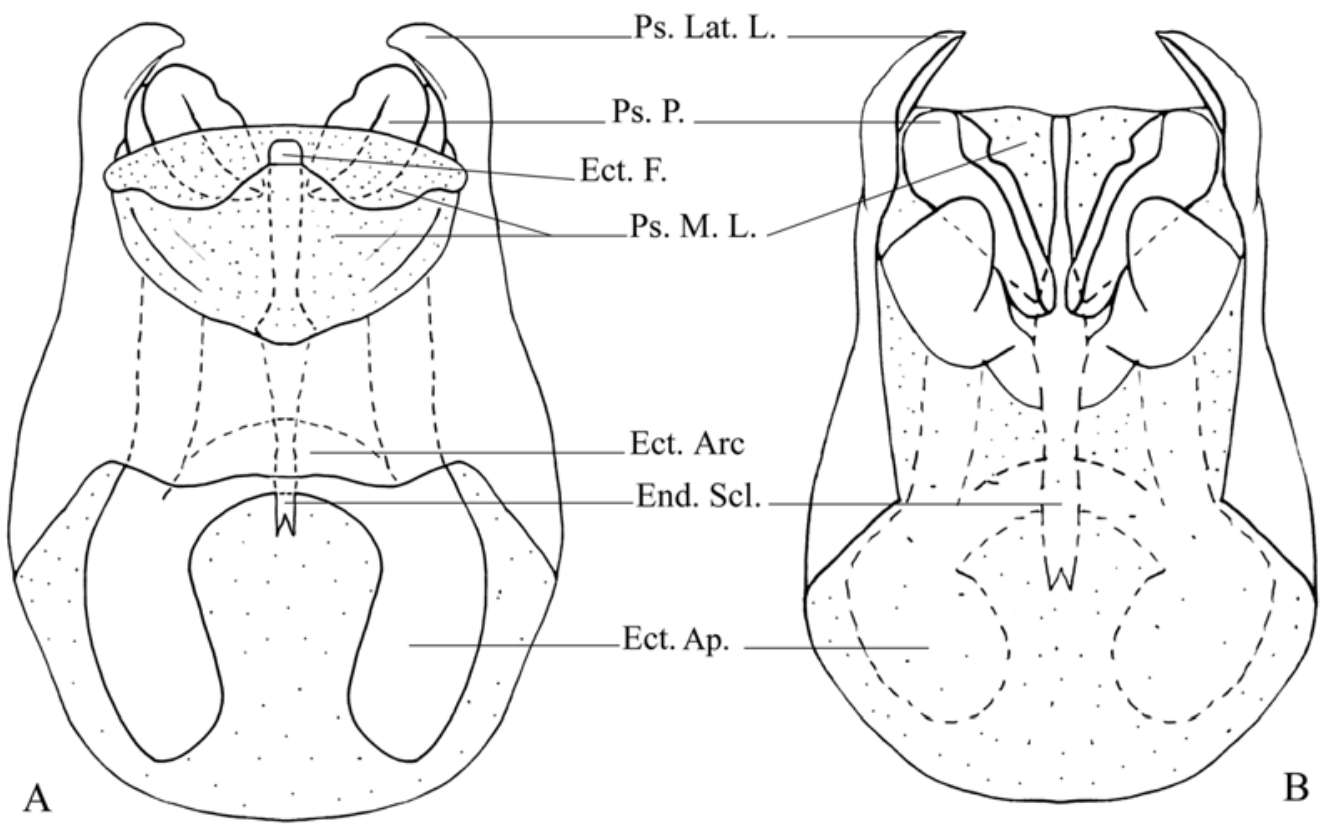

B

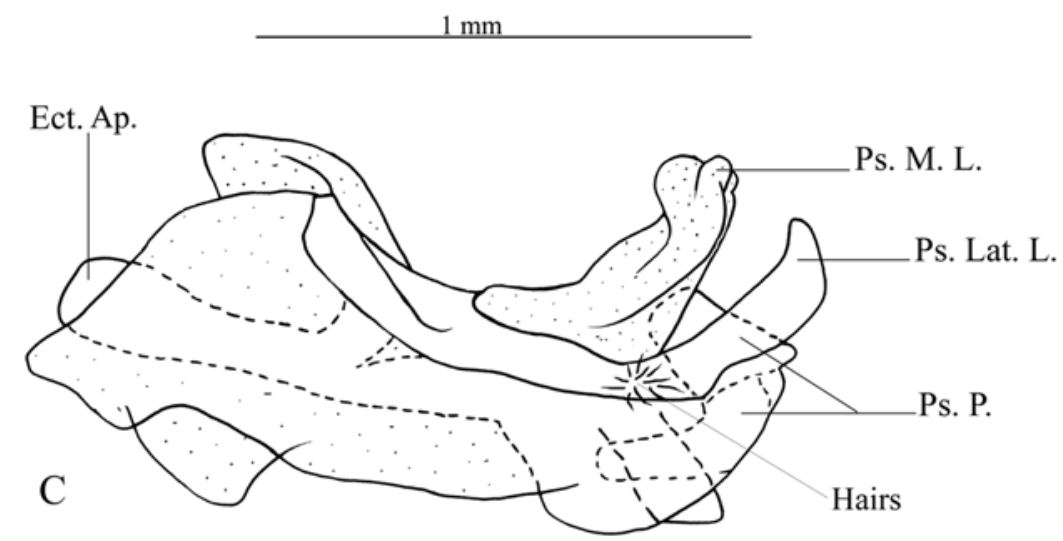

Fig. 2 - Male genitalia of $P$. arenita sp. nov. in A. dorsal, B. ventral and C. lateral view. Abbreviations: Ps. Lat. L.: pseudepiphallic lateral lobes / Ps. P.: pseudepiphallic paramere / Ps. M. L.: pseudepiphallic median lobe / Ect. F.: ectophallic fold / Ect. Arc: ectophallic arc/ Ect. Scl.: ectophallic sclerite / End. Ap.: endophallic sclerite.

Phalangopsis bauxitica Mews and Sperber sp. nov.

(Figs. 4-5)

Holotype. 1 male: 04.ix. 1983, Gruta do Piriá, Viseu, PA, Brasil, $\left(01^{\circ} 12^{\prime} 10^{\prime \prime} \mathrm{S} 46^{\circ} 17^{\prime} 36^{\prime \prime} \mathrm{W}\right)$, (A.L. Henriques and W. de Souza leg.), INPA.

Etymology. The specific epithet was derived from the word "Bauxite", which is the typical geological formation of Piriá cave.

Diagnosis. This species can be distinguished from the other described Phalangopsis species by the following combination of characteristics: (i) Ocelli absent; (ii) a quadrangular fore wing covering the first abdominal tergite (Fig. 4C), (iii) stridulatory vein and pars stridens absent; (iv) tympanum absent on the outer face of the fore tibia. Male genitalia: (v) pseudepiphallic lateral lobes slightly curved towards the center, one towards the other, with small hairs at the apex of the pseudepiphallic lateral lobes (Fig. 5C); (vi) pseudepiphallic parameres narrow, reaching the base of the lateral lobes (Fig. 5B); (vii) pseudepiphallic median lobes prominent, forming an approximately $90^{\circ}$ angle with the lateral lobe (Fig. 5C); 


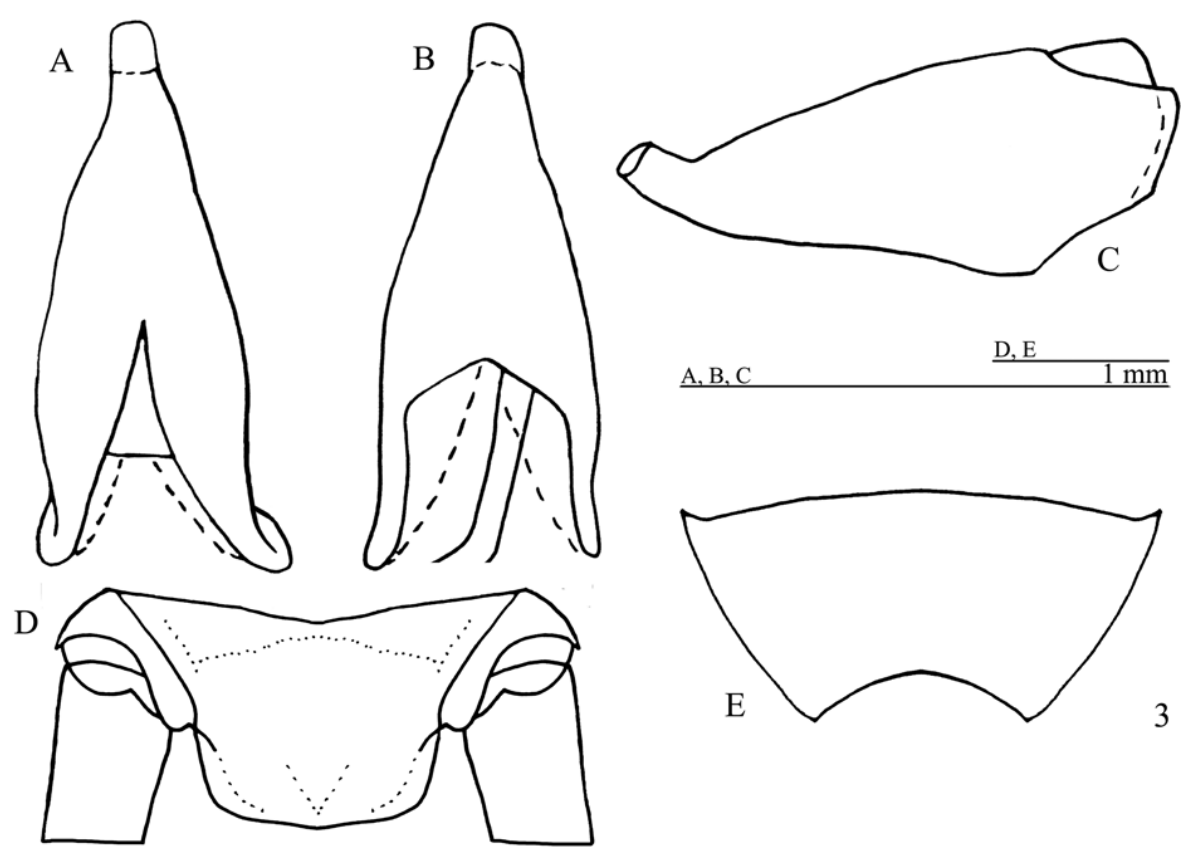

Fig. 3 - P. arenita sp. nov. Female copulatory papilla. A. dorsal, B. ventral and C. lateral views. D. Female supra-anal plate. E. Female subgenital plate.

(viii) ectophallic fold external to the medium lobe, curved to the dorsum, accompanying the medium lobe along all extension. Female unknown.

Male. Measurements $(\mathrm{mm})(\mathrm{n}=1)$ : body length 19.00; maximum eye width 3.80; pronotal length 3.50; pronotal width 5.45; wing width 2.10; wing length 1.90 . Head with light brown coloring. Top of the head dark brown, vertex and fastigium light brown. Gena as in Figure 4A. Tuft of hairs between compound eyes. White clypeus, labium and palpi. Maxillary palpi rounded on the apex, with a yellowish light brown color. Rounded face in frontal view (Fig. 4B). Ocelli absent. Dark brown scape. Flagellum uniformly brown. Body dark brown. Pronotum dark brown, with a yellowish light brown deep median depression, narrow, with prominent lateral lobes. Fore wing covering the first abdominal tergite (Fig. 4A), dark brown coloring except for the border white. Quadrangular shaped (Fig. 4C). Sc, R, M and A1 veins of fore wing present, stridulatory vein and pars stridens $\mathrm{ab}-$ sent, a Sc vein separates the dorsal champ of the lateral field and $\mathrm{Cu}_{1}$ outlines the wing (Fig. 4C). Posterior border of the wing is intumesced, glandular and pubescent
(Fig. 4A - stippled area). Tympanum absent on the outer face of the fore tibia, drop-shaped. Fore and median femur light brown; fore and median tibiae light brown; fore and median tarsomeres light brown. Hind femur light brown; hind tibia light brown with a light yellowish base and a light colored strip in the middle. Observed from an external lateral view, darker transversal stripes on the superior dorsum of hind tibia. Hind tibia with four pairs of sub-apical spurs, the external always larger than the internal; 23 spines on the inner margin, between sub-apical spurs, and 34 on the outer margin. Seven apical spurs, with the external being smaller than the internal. Supra-anal plate straight at the apex (Fig. 4D). Subgenital plate as long as broad, with rounded apex, convex shaped (Fig. 4E). Pseudepiphallic lateral lobes with the same diameter in all extension, slightly curved towards the center, one towards the other, with small hairs at the apex of the pseudepiphallic median lobe (Fig. 5C); pseudepiphallic parameres narrow, reaching the base of the lateral lobes (Fig. 5B); pseudepiphallic median lobes prominent, forming a $90^{\circ}$ angle with the lateral lobe; base of the pseudepiphallus laterally wide, extending towards the center of the genitalia (Fig. 5C); 


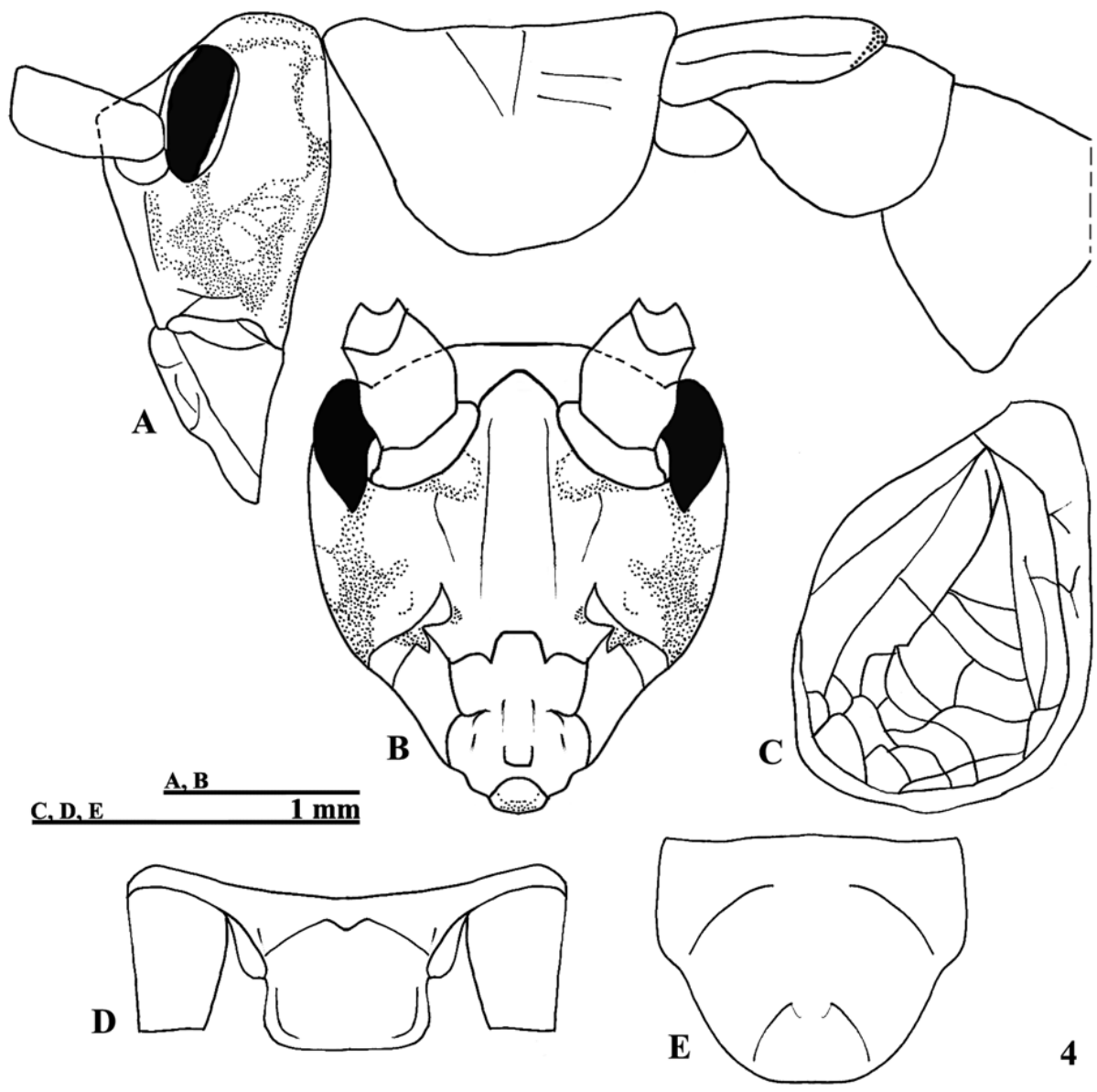

Fig. 4 - Male of Phalangopsis bauxitica sp. nov. A. Lateral view of the head and pronotum. B. Frontal view of the head. C. Dorsal view of the forewing. D. Supra-anal plate. E. Subgenital plate.

ectophallic arc in posterior position; ectophallic fold external to the medium lobe, curved towards the dorsum, accompanying the medium lobe along all extension; ectophallic apodeme basal, long and narrow; endophallic sclerite small, as simple "guiding rod" (Fig. 5A-C).

Material examined. One male holotype: 04.ix. 1983, Gruta do Piriá, Viseu, PA, Brazil, $\left(01^{\circ} 12^{\prime} 10^{\prime \prime} \mathrm{S}\right.$ $46^{\circ} 17^{\prime} 36^{\prime \prime}$ W), (A.L. Henriques and W. de Souza leg.), INPA.

\section{DISCUSSION}

The crickets Phalangopsis arenita sp. nov. were collected in the Maroaga cave, Presidente Figueiredo, Amazonas State. The Maroaga cave is an arenite formation of $600 \mathrm{~m}$ length with a small watercourse in its interior (A.L. Henriques, pers. com.). Phalangopsis bauxitica sp. nov. was found in the Piriá cave located in Viseu, Pará State $\left(1^{\circ} 12^{\prime} 10^{\prime \prime} \mathrm{S} 46^{\circ} 17^{\prime} 36^{\prime \prime} \mathrm{W}\right)$. The Piriá cave is a bauxitic formation described by Pinheiro et al. (2001).

The $P$. arenita sp. nov. and P. bauxitica sp. nov. are different from $P$. longipes by their posterior border of pronotum, metanotum and first tergite dark brown. Fore wing reduced, not crossing the metanotum. Pars stridens with 18-22 teeth and supra-anal plate pubescent. They differ from P. flavilongipes by the presence of a pale yellow uniform coloration, third apical internal spur longer than the second. Fore wing without stridulatory vein. Apical border of fore wing rounded and possibly glandular (see Desutter-Grandcolas 1992). They differ from $P$. gaudichaudi by the presence of developed ocelli, forming an equilateral triangle. Between 

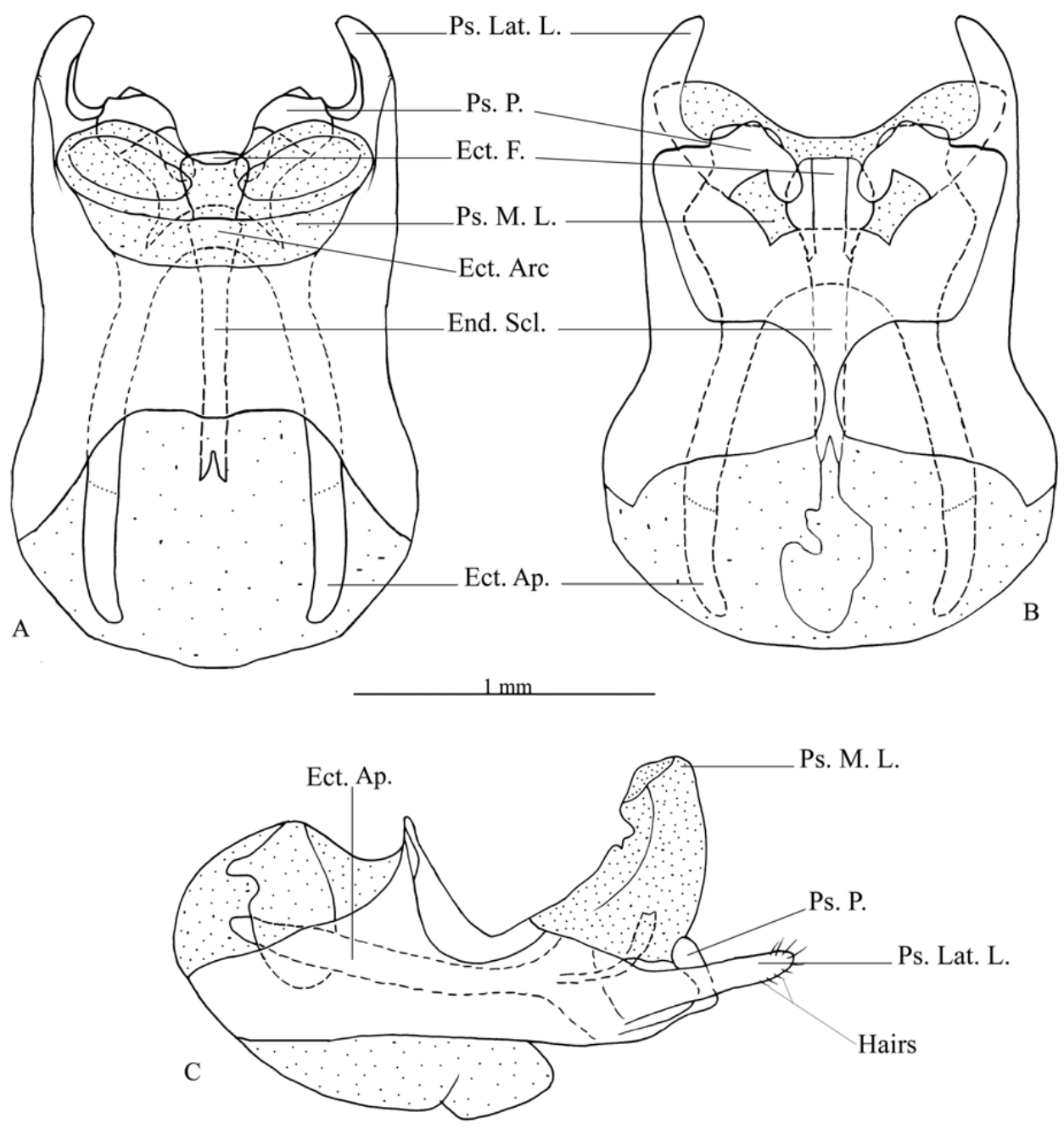

Fig. 5 - Male genitalia of P. bauxitica sp. nov. A. dorsal, B. ventral and C. lateral view. Abbreviations: Ps. Lat. L.: pseudepiphallic lateral lobes / Ps. P.: pseudepiphallic paramere / Ps. M. L.: pseudepiphallic median lobe / Ect. F.: ectophallic fold / Ect. Arc: ectophallic arc/Ect. Scl.: ectophallic sclerite/End. Ap.: endophallic sclerite.

the vertex and the fastigium there is unevenness. Tympanum absent. They differ from P. speluncae by the presence of three pairs of sub-apical spurs (contrasting with the other species that have four pairs of sub-apical spurs) and bilobed subgenital plate. They differ from $P$. carvalhoi by the presence of the second apical spur (medium) three times larger than the first apical spur (internal), and the first largest than the third apical spur (external).

The Phalangopsis genus is represented by six species distributed in South America, P. longipes occurs in Meridional America, P. flavilongipes in French Guiana and the other four described species occur in Brazil: $P$. carvalhoi in Tapeuá, Rio Paru do Leste, Amazonas State, P. speluncae in Santa Bárbara, Minas Gerais State and P. aureopubescens in Lençóis Paulista, São Paulo State. The original description of P. gaudichaudi does not have any information on type-locality, just quoting "Brazil". The lack of this information makes it impossible to have an accurate map of the genus' geographical distribution since it records only the Brazilian species distribution, and makes it difficult to plan field trips to collect supplementary material of this species.

The Phalangopsis crickets live in the litter of the 
forest and are active at night, hiding during the day in caves or other natural cavities (Desutter 1990, DesutterGrandcolas 1992). Hence, Phalangopsis could comprise cavicolous (P. longipes), troglophilous ( $P$. carvalhoi and $P$. speluncae) and straminicolous (P. gaudichaudi and $P$. flavilongipes) species (Desutter-Grandcolas 1998). This genus as well as Endecous Saussure 1878, constitutes a group with diverse habits, suitable for comparative studies on the evolution of troglobiomorphic features (Christiansen 1962, 1992, Ahearn and Howarth 2005).

Some genera of Phalangopsidae crickets present analogous ventral glands in the apical border of the fore wing, which are inflated and present secretion. It is the case of some species of Eidmanacris Chopard 1956 (Luzarinae), of the ventral hair of the wing of Guabamima De Mello 1992 (Luzarinae) and of Phalangopsis (Phalangopsinae). The appearance of this character seems to be independent (or with no homology), because it appears in different subfamilies. Besides, the Eidmanacris and Guabamima glands probably produce volatile pheromones to attract co-specific females for the copula, since in these genera there is no production of calling sounds.

\section{ACKNOWLEDGMENTS}

Thanks are due to Augusto L. Henriques, curator of the Collection of Invertebrates of the Instituto Nacional de Pesquisas da Amazônia/Coordenação de Pesquisas em Entomologia (INPA/CPEn), for lending the biological material; Dr. Edward Brede (Max-Planck-Institut für Limnologie, Plön, Germany) for English revision; Briguitte Lechner (Max-Planck-Institut für Limnologie, Plön, Germany) was extremely helpful providing the literature. This work was financed by "Conselho Nacional de Desenvolvimento e Tecnologia" (CNPq), "Coordenação de Aperfeiçoamento de Pessoal de Nível Superior" (CAPES), and "Fundação de Amparo à Pesquisa do Estado de Minas Gerais" (FAPEMIG), and was partially elaborated during a period of scientific training of CFS at the Max-Planck-Institute for Limnology, Plön, Germany.

\section{RESUMO}

Aqui foram descritas duas espécies novas do gênero Phalangopsis Serville, 1831 da Floresta Amazônica brasileira.
A genitália masculina e a papila copulatória feminina são descritas, bem como uma combinação de características diagnósticas para separar ambas as novas espécies das outras espécies descritas. As principais características morfológicas foram discutidas.

Palavras-chave: região neotropical, Brasil, grilos, Phalangopsini.

\section{REFERENCES}

Ahearn GA And Howarth FG. 2005. Physiology of cave arthropods in Hawaii. J Exp Zool 222: 227-238.

ChOPARD L. 1956. Some crickets from South America (Grylloidea and Tridactylloidea). Proc US Nat Mus 106: 241-293.

Christiansen K. 1962. Proposition pour la classification dès animaux cavernicoles. Spelunca Mem 2: 76-78.

Christiansen K. 1992. Biological processes in space and time: cave life in the light of modern evolutionary theory. In: CAMACHO AI (Ed), The Natural History of Biospeleology. Madrid: Mus Nac Cienc Nat 42: 454-478.

Costa Lima A And Costa Leite I. 1953. Um novo grilo cavernicola (Orthoptera, Gryllidae, Phalangopsidae). An Acad Bras Cienc 25: 169-170.

DE Mello FAG. 1992. A new genus of long-legged crickets from the forests of Eastern Brazil (Orthoptera: Grylloidea: Phalangopsidae). Rev Agric 67: 125-131.

Desutter L. 1987. Structure et évolution du complexe phalique des Grylloidea (Orthoptéres) et classification des genres néotropicaux de Grylloidea: première partie. Ann Soc Entomol Fr 23: 213-240.

Desutter L. 1988. Structure et évolution du complexe phalique des Grylloidea (Orthoptéres) et classification des genres néotropicaux de Grylloidea: deuxième partie. Ann Soc Entomol Fr 24: 343-373.

DeSUTTER L. 1990. Etude phylogénétique, biogéographique et écologique dês Grylloidea néotropicaux (Insectes, Orthoptéres). Université Paris XI - Orsay, Thése de Doctorat, $347 \mathrm{p}$.

Desutter-Grandcolas L. 1992. Les Phalangopsidae de Guyanne française (Orthoptéres, Grylloidea): systématique, éléments de phylogénie et de biologie. Bull Mus Natl Hist Nat Sect A: Zool Biol Ecol Anim 14: 93-177.

Desutter-GrandCOlas L. 1998. Grylloidea. In: JUBERTHIE C AND DECU V (Eds), Encyclop. biospeleol, tome II: $989-1001$.

Desutter-Grandcolas L. 2003. Phylogeny and the evo- 
lution of acoustic communication in extant Ensifera (Insecta, Orthoptera). Zool Scripta 32: 525-561.

EAdEs DC, OTTE D AND NASKRECKi P. 2007. Orthoptera Species File Online. Version 2.2. Accessible at $<$ http://osf2.orthoptera.org $>$. Retrieved at July $26^{\text {th }}, 2007$.

Melo-Leitão C. 1937. Un Gryllide et deux Mantides nouveaux du Brésil (Orth.). Rev Entom 7: 11-18.

OTTE D. 1992. Evolution of cricket songs. J Orthoptera Res 1: $25-49$.

Pinheiro RVL, Maurity C, Henriques AL, Silveira LT, LOPES PRC, SilveirA OT, PAIVA ALFA, VERISSIMO CUV AND KERN DC. 2001. As grutas bauxíticas da Serra do Piriá, PA. Bol Mus Par Emilio Goeldi (Série Ciências da Terra) 13: 3-97.
SAUssure MH. 1874. Études sur les Myriapodes et les Insectes. In: EDWARDS MM Mission scientifique au Mexique et dans L'Amerique Centrale, recherches zoologique, pour servir à l'histoire de la faune de l'Amérique Centrale et du Mexique. Impbordererie Impériale, Paris. Sixième partie, p. 451-454.

SAUSSURE MH. 1878. Mèlanges orthoptèrologiques. VIème fascicule. Gryllides (2ème partie). Mém Soc Phys et Hist Nat 25: 369-702.

Serville JGA. 1831. Revue méthodique des insectes de 1'ordre des Orthoptères. Ann Sci Nat Zool Biol Anim 22: 166-167.

WIENDL FM. 1970. Uma nova espécie de Arachnomimus brasileira (Orthoptera, Phalangopsidae). Rev Agric 45: 73-74. 